\title{
polymers
}

ISSN 2073-4360

www.mdpi.com/journal/polymers

Article

\section{Temperature Induced Solubility Transitions of Various Poly(2-oxazoline)s in Ethanol-Water Solvent Mixtures}

Hanneke M. L. Lambermont-Thijs ${ }^{1}$, Huub P. C. van Kuringen ${ }^{1}$, Jeroen P. W. van der Put ${ }^{1}$, Ulrich S. Schubert ${ }^{1,2,3, *}$ and Richard Hoogenboom ${ }^{1,4, *}$

1. Laboratory of Macromolecular Chemistry and Nanoscience, Eindhoven University of Technology, P.O. Box 513, 5600 MB Eindhoven, The Netherlands; E-Mails: h.lambermont@tue.nl (H.M.L.L.-T.); h.p.c.v.kuringen@student.tue.nl (H.P.C.K.); j.p.w.v.d.put@student.tue.nl (J.P.W.P.)

2. Laboratory of Organic and Macromolecular Chemistry, Friedrich-Schiller-University Jena, Humboldtstrasse 10, 07743 Jena, Germany

3. Dutch Polymer Institute, John F. Kennedylaan 2, 5612 AB Eindhoven, The Netherlands

4. Supramolecular Chemistry group, Department of Organic Chemistry, Ghent University, Krijgslaan 281 S4, 9000 Ghent, Belgium

* Author to whom correspondence should be addressed; E-Mails: ulrich.schubert@ uni-jena.de (U.S.S.); r.hoogenboom@tue.nl (R.H.).

Received: 13 June 2010; in revised form: 3 August 2010 / Accepted: 6 August 2010 /

Published: 10 August 2010

\begin{abstract}
The solution behavior of a series of poly(2-oxazoline)s with different side chains, namely methyl, ethyl, $n$-propyl, isopropyl, $n$-butyl, isobutyl, pentyl, hexyl, heptyl, octyl, nonyl, phenyl and benzyl, are reported in ethanol-water solvent mixtures based on turbidimetry investigations. The LCST transitions of poly(2-oxazoline)s with propyl side chains and the UCST transitions of the poly(2-oxazoline)s with more hydrophobic side chains are discussed in relation to the ethanol-water solvent composition and structure. The poly(2-alkyl-2-oxazoline)s with side chains longer than propyl only dissolved during the first heating run, which is discussed and correlated to the melting transition of the polymers.
\end{abstract}

Keywords: poly(2-oxazoline); solubility transitions; ethanol-water; LCST; UCST; thermoresponsiveness 


\section{Introduction}

The cationic ring opening polymerization (CROP) of 2-oxazolines, which can be used to prepare well defined polymers with narrow molar mass distributions, was discovered back in 1966 [1-4]. In recent years, poly(2-oxazoline)s received renewed interest due to their potential use as biomaterials [5-7] and/or 'smart' materials [5,8]. As biomaterials, poly(2-oxazoline)s can compete with poly(ethylene glycol) with regard to 'stealth' behavior and biocompatibility while their synthetic scaffold is much more versatile [7].

'Smart' materials are materials that respond to changes in the environment. A wide range of response factors, i.e., triggers, have been developed such as chemical or biological agents for sensors [9-11], mechanical forces [12,13], UV-vis or near-IR irradiation [14,15], magnetic and electrical fields [16,17] as well as temperature [18]. The response of the 'smart' material to the external triggering event can be manifold too, ranging from surface energy switching [10,19], a shape change [20], variation in absorption or emission [12], or the material can undergo a phase transition [15,18]. 'Smart' polymeric materials that undergo a phase-transition in water are in particular interesting for the development of responsive solutions, e.g., for the development of diagnostic tools and sensors [21-23]. The majority of such temperature induced solubility transitions are based on the lower critical solution temperature (LCST) behavior of polymers in aqueous solution, i.e., the polymer is dissolved at low temperature by favorable hydration while increasing the temperature leads to an entropy driven dehydration resulting in a collapse of the hydrophobic polymer chains [18,21,23]. Polymers exhibiting the opposite upper critical solution temperature (UCST) behavior in aqueous solutions, i.e., insoluble at low temperatures and soluble at elevated temperatures, are much less common [24-26].

'Smart' poly(2-oxazoline)s that undergo a LCST phase transition in water are also accessible by compensating the hydrophilicity of the polyamide backbone with small hydrophobic side-chains. In fact, poly(2-oxazoline)s with ethyl, $i$-propyl and $n$-propyl side chains are known to exhibit LCST transitions at $\sim 65^{\circ} \mathrm{C}, \sim 36{ }^{\circ} \mathrm{C}$ and $\sim 24^{\circ} \mathrm{C}$, respectively [27-29]. It was previously demonstrated that the LCST transition of copolymers of 2-ethyl-2-oxazoline (EtOx) and 2- $n$-propyl-2-oxazoline (PropOx) is almost as robust as the LCST transition of the most studied polymer poly( $N$-isopropylacrylamide $)$ with regard to concentration and $\mathrm{pH}$ dependence while the reversibility of the poly(2-oxazoline) phase transition is even better [30]. It should be noted however that PNIPAM exhibits type II LCST behavior [31] and PEtOx exhibits type I LCST behavior [32], resulting in an increased molar mass dependence for the LCST of PEtOx. The thermal transition of poly(2-i-propyl-2-oxazoline) (i-PropOx) is reversible when cycled, but upon prolonged heating above the phase transition temperature crystallization occurs causing irreversible precipitation since the melting temperature of the crystals (almost $200{ }^{\circ} \mathrm{C}$ ) is far beyond the boiling point of water [33,34]. In contrast to the LCST behavior, there are no poly(2-oxazoline)s reported with a UCST transition in water. Nonetheless, we previously reported UCST behavior of poly(2-phenyl-2-oxazoline) (PhOx), copolymers of PhOx with 2-nonyl-2-oxazoline (NonOx), 2-methyl-2-oxazoline (MeOx) or EtOx as well as copolymers of NonOx and EtOx in aqueous ethanol solutions [35-37].

Tuning the solution behavior of polymers in binary solvent mixtures was already demonstrated by Shultz and Flory [38], as well as Wolf and Blaum [39] for non-aqueous solvent mixtures, resulting in 
better polymer solubility compared to the individual pure solvents. However, little is known about the solution behavior of polymers in water-ethanol mixtures, despite such mixtures being known to exhibit interesting abnormal mixing properties due to the presence of hydration shells around the ethanol molecules [40-42]. This peculiar mixing behavior has been demonstrated to result in solubility maxima for several drug molecules in aqueous ethanol $[43,44]$ as well as for poly(methyl methacrylate) $[45,46]$ and several poly(2-oxazoline)s as already mentioned previously [33-35].

Our previous efforts in evaluating the solution properties and phase transitions of poly(2-oxazoline)s in ethanol-water solvent mixtures were limited to a few selected monomers, namely $\mathrm{MeOx}, \mathrm{EtOx}, \mathrm{PhOx}$ and NonOx, and copolymers thereof. To establish a more detailed insight into the effect of side-chain substituent on the solution behavior of poly(2-oxazoline)s, the current study focuses on the solubility behavior of a range of poly(2-oxazoline) homopolymers with various $n$-alkyl substituents, two branched side chains, namely isopropyl and isobutyl, as well as phenyl and benzyl substituents. All investigated monomers and corresponding polymer structures are depicted in Scheme 1 . The solubility behavior of these homo poly(2-oxazoline)s was investigated in ethanol-water solvent mixtures, which will be discussed in the following.

Scheme 1. Schematic representation of the structures of the investigated 2-oxazolines and the corresponding poly(2-substituted-2-oxazoline)s prepared by cationic ring-opening polymerization (CROP).<smiles>CC1=NCCO1</smiles>

MeOx<smiles>CCCC1=NCCO1</smiles>

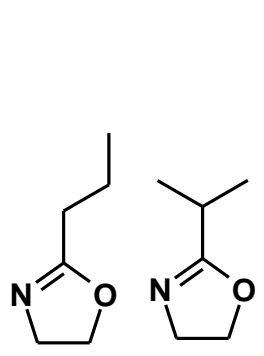

PropOx

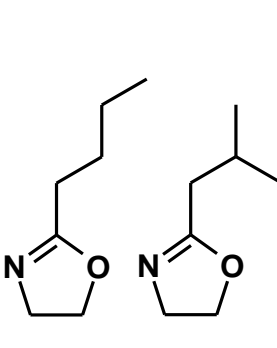

ButOx

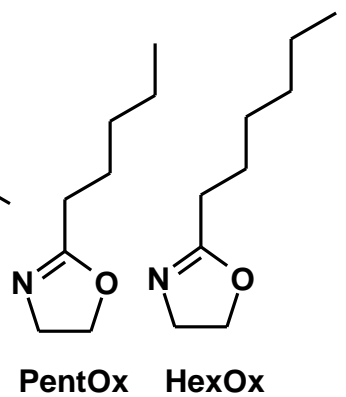

HexOx<smiles>CCCC1=NCCC1</smiles>

HeptOx<smiles>CCCCCCCCC1=NCCO1</smiles>

OctOx

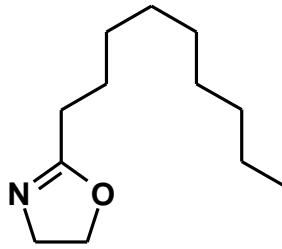

NonOx<smiles>c1ccc(C2=NCCO2)cc1</smiles>

PhOx BenzOx<smiles>CC(=O)OCCOC(=O)OC(C)C</smiles>

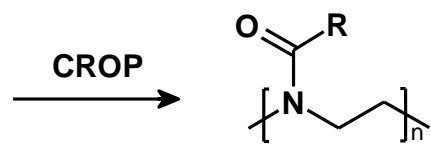

\section{Results and Discussion}

The investigated poly(2-oxazoline)s (see Scheme 1; the polymers will be abbreviated by the monomer names as given in Scheme 1 in the following discussion) were prepared by microwave-assisted polymerization of the corresponding monomers using methyl tosylate as initiator and acetonitrile as solvent as described in our previous publication [47]. The monomers were prepared by reaction of the corresponding nitriles with 1-amino-2-ethanol using zinc acetate as catalyst [48]. All investigated polymers have a degree of polymerization of $60 \pm 5$ and the polydispersity indices, 
determined by size exclusion chromatography, were mostly below 1.20 , indicating relatively narrow molar mass distributions.

The solubility behavior of this series of poly(2-oxazoline)s was investigated at a polymer concentration of $5 \mathrm{mg} / \mathrm{mL}$ in ethanol-water solvent mixtures ranging from pure water to pure ethanol. Initially the solvent composition was varied in steps of $20 \mathrm{wt} \%$ ethanol and the interesting regimes, i.e., solvent compositions around observed solubility transitions, were investigated in further detail with steps of $5 \mathrm{wt} \%$ ethanol to elucidate all transition temperatures. The solubility screening was performed by turbidimetry of the polymer solutions as a function of temperature in the range from -20 to $105{ }^{\circ} \mathrm{C}$ (for aqueous solutions the lower temperature was limited to $0{ }^{\circ} \mathrm{C}$ ). The resulting transmittance versus temperature curves together with visual inspection of the solutions, if required also during the heating/cooling cycles, were used to evaluate the solubility behavior of the poly(2-oxazoline)s. As such, polymers that were soluble or insoluble over the entire temperature range were identified. In addition, LCST and UCST transitions were observed as well as polymers that only dissolved during the initial heating run and remained soluble throughout the remaining heating/cooling cycles (dissolution upon heating). Representative transmittance versus temperature plots of these three observed solubility transitions are depicted in Figure 1. The LCST transitions are illustrated by high transmittance at lower temperatures where the polymer is molecularly dissolved and a decrease in transmittance upon heating indicative of polymer precipitation. The cloud point of the LCST transition is taken as the $50 \%$ transmittance point during the transition. The UCST transitions show the reverse behavior, i.e., $0 \%$ transmittance at low temperature and an increase in transmittance upon heating, and the cloud point is taken as the 50\% transmittance points. Dissolution upon heating is evidenced by strong scattering at low temperature resulting from the presence of polymer particles that pass between the light source and the detector. Upon heating the transmittance increases indicative of a clear polymer solution. Again the dissolution temperature is taken as the 50\% transmittance point during the first heating ramp. In all cases, the transmittance for the clear polymer solutions decreases to $\sim 80 \%$ upon heating, which is a measuring artefact due to temperature dependence of the used detector.

Figure 1. Representative transmittance versus temperature plots for the three different phase transition phenomena that were observed for polymer solutions in this contribution, namely LCST and UCST behavior as well as dissolution upon heating.
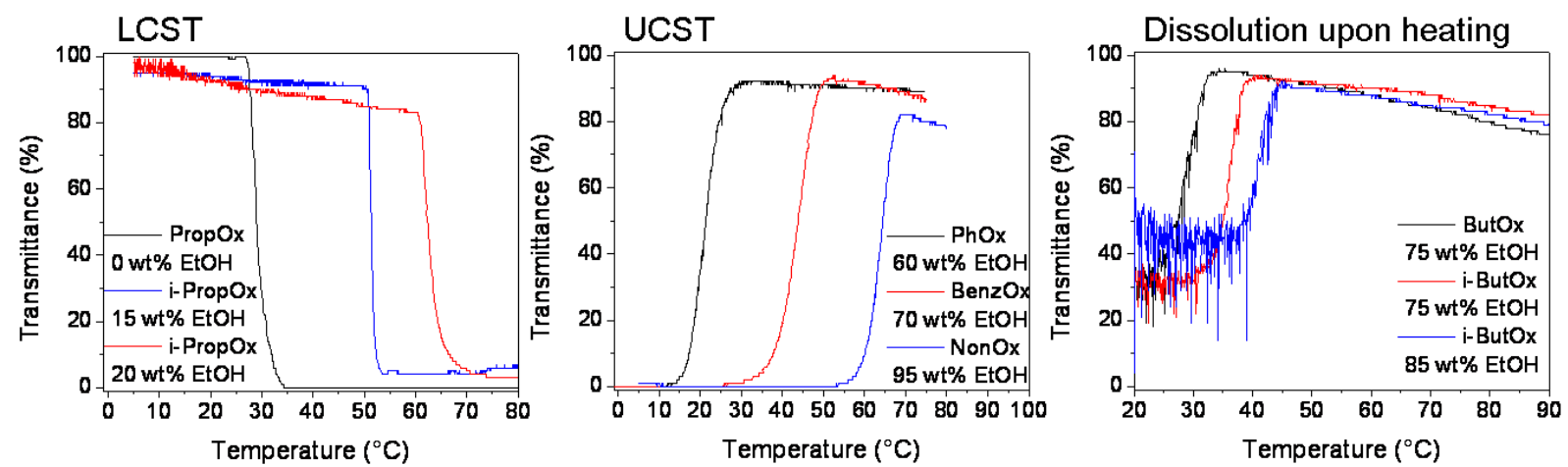

An overview of the qualitative solubility results of all investigated poly(2-oxaozline)s is provided in Figure 2. The main observations and trends in this phase diagram will first be discussed followed by a 
more detailed discussion of the different phenomena and phase transition temperatures. The two most hydrophilic polymers, $\mathrm{MeOx}$ and EtOx, are soluble in water as well as all aqueous ethanol solutions. Even though EtOx with a DP > 100 is known to exhibit a LCST transition in water [27,30,32], the shorter polymer with DP 60 investigated in this study is soluble in the investigated temperature regime in agreement with previous reports [30,47]. When the hydrophobicity of the poly(2-oxazoline)s is increased with an additional $\mathrm{CH}_{2}$ group, PropOx and i-PropOx, the polymers undergo a LCST transition in water and water rich ethanol solutions. The difference between these two polymers will be addressed in more detail later on. All remaining poly(2-oxazoline)s with larger hydrophobic side-chains were found to be insoluble in water and aqueous ethanol solutions containing up to 35 wt $\%$ ethanol. When the ethanol content of the solutions is just high enough to ensure dissolution of these hydrophobic polymers, the solutions revealed reversible UCST behavior, i.e., at low temperature the polymers are insoluble and upon increasing the temperature the polarity of the solvent mixture decreases resulting in dissolution of the polymers. The amount of ethanol that is required for this UCST behavior increases with increasing hydrophobicity of the side chains. It should be noted that the poly(2-oxazoline)s with aromatic side chains exhibit UCST behavior at much lower ethanol contents compared to the poly(2-alkyl-2-oxazoline) analogues with similar number of carbon atoms. This observation can be ascribed to the higher polarity of the aromatic side chains compared to the aliphatic side chains as well as a decreased shielding of the amide groups by the more rigid aromatic substituents. Upon further increasing the ethanol content, the poly(2-n-alkyl-2-oxazoline)s do not directly dissolve in the solvent mixture, but they dissolve during the first heating run. This initial heating is required to destabilize the crystals that are present in these semi-crystalline polymers allowing solvent penetration of the crystals and dissolution of the individual polymer chains. Previously, it was found that NonOx with a DP of 100 was also only soluble after heating. However, in the current study NonOx with a DP of 60 is studied and the observed difference in dissolution behavior indicates that either a smaller crystalline fraction is present in the shorter polymer or the formed crystalline domains are smaller and less stable.

Figure 2. Solubility overview for poly(2-alkyl-2-oxazoline)s in water-ethanol mixtures $(5 \mathrm{mg} / \mathrm{mL})$.

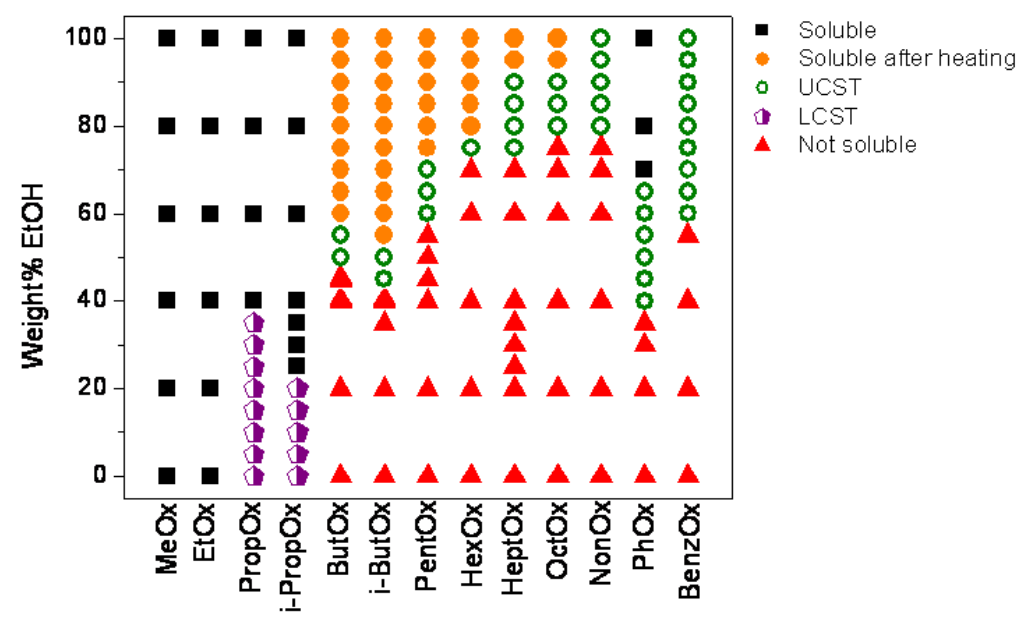

The cloud points that were determined for the LCST transition of PropOx and i-PropOx in aqueous ethanol are shown as a function of ethanol content in Figure 3. The cloud points in water are slightly 
higher than the reported values of $36{ }^{\circ} \mathrm{C}$ and $24{ }^{\circ} \mathrm{C}$ for i-PropOx and PropOx, respectively, due to the relatively low DP of 60 . The higher cloud points of shorter polymers can be ascribed to the stronger influence of the easily hydrated and hydrophilic end-groups of the polymers, which are a methyl group resulting from initiation and a hydroxyl group resulting from termination. From Figure 3 it is clear that i-PropOx is more hydrophilic compared to PropOx, which is due to the smaller size of the isopropyl group resulting in less effective shielding of the hydrophilic amide groups compared to the $n$-propyl side chains. Generally it would be expected that decreasing the solvent polarity by adding the less polar solvent ethanol to water, improves the solubility of the polymers and, thus, increasing the cloud points. However, the opposite effect is observed for both polymers upon addition of $5 \mathrm{wt} \%$ ethanol. This can be ascribed to the "water structure making" effect of small amounts of ethanol, i.e., when a small amount of ethanol is added, these molecules will be surrounded by a cage of water molecules, so-called hydrophobic hydration. It has been suggested that the presence of such "structured" water cages around ethanol decreases the hydration of the polymer chain resulting in decreased solubility and, thus, a lower cloud point [26]. A similar effect is described for longer n-alcohols (C4-C6) at low concentrations causing a decrease in cloud point for ethylene oxide-propylene oxide copolymers $[49,50]$. The different behavior between PropOx and i-PropOx upon increasing the ethanol fraction most likely arises from hydrophobic solvation of the side chain by ethanol molecules. Upon increasing the amount of ethanol not all ethanol molecules can be hydrated and the remaining free ethanol can solvate the polymer side-chains. This ethanol solvation will be more effective for i-PropOx due to its lower hydrophobicity, which is proposed to induce the different behavior of the two polymers. These results clearly indicate the importance of the non-ideal mixing behavior ofethanolwater solvent mixtures for the solubility transitions of polymers.

Figure 3. Cloud points as function of wt $\%$ ethanol for the LCST transitions of poly(2-propyl-2-oxazoline) (PropOx) and poly(2-isopropyl-2-oxazoline) (i-PropOx) at $5 \mathrm{mg} / \mathrm{mL}$ concentration.

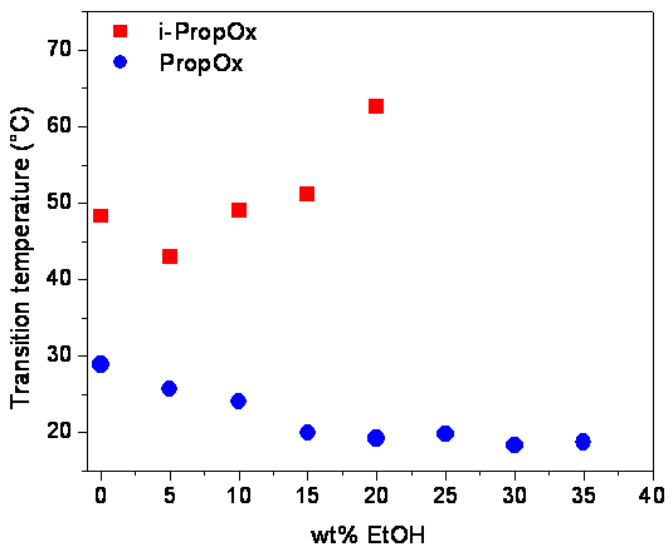

The cloud points obtained during the UCST transitions of the more hydrophobic poly(2-oxazoline)s are summarized in Figure 4. The results for the poly(2-alkyl-2-oxazoline)s are depicted in Figure 4, left, revealing three groups of polymer. The first group is formed by ButOx and i-ButOx revealing a narrow UCST regime of around $50 \mathrm{wt} \%$ ethanol content. The lower ethanol content required for dissolution and UCST behavior of i-ButOx indicates better solubility compared to ButOx. However, 
the lower cloud point of ButOx with $50 \mathrm{wt} \%$ ethanol indicates that, at this specific solvent ratio, the ButOx is better soluble compared to the i-ButOx. Again, it is very difficult to conclusively interpret these results, but it is clear that the water-ethanol structure formation and the interactions with the hydrophobic and hydrophilic parts of the polymers are of major importance for the UCST behavior in this solvent composition regime.

The second group of polymers is formed by PentOx and HexOx that combine an intermediate hydrophobic side chain with the hydrophilic polymer backbone. The observed behavior for PentOx, a steep decrease in cloud points from 60 to $70 \mathrm{wt} \%$ ethanol is similar to the observed solubility transitions of poly(methyl methacrylate) in water-ethanol solvent mixtures [30,51]. This peculiar solubility behavior is due to the clustering of water molecules in ethanol rich solutions. At 80 wt $\%$ ethanol, water is mostly present as individual water molecules driving the formation of a water hydration shells around the polymer by interactions with the amide groups [40,50] The resulting hydration shell acts as a compatibilizing layer between the solvent mixture and the polymer. When decreasing the amount of ethanol from $80 \mathrm{wt} \%$ to $60 \mathrm{wt} \%$ the water cluster size gradually increases [40] and, therefore, the driving force for polymer hydration decreases since hydration now competes with water-water hydrogen bonding in the clusters. Therefore, the cloud points strongly decrease with increasing water content. Even though only one cloud point is observed for HexOx with $75 \mathrm{wt} \%$ ethanol, it can be speculated that this polymer has a similar behavior as PentOx with an even steeper decrease in cloud point with increasing ethanol content pushing the cloud points outside the investigated temperature range with 70 and $80 \mathrm{wt} \%$ ethanol.

The third group of polymers contains large hydrophobic side chains that suppress the solubilization effect of the formation of a hydration layer around the amide groups, i.e., the amide groups are shielded from the solution by the long alkyl chains. Therefore, the cloud point slightly decreases with increasing ethanol content, which can be ascribed to the slightly decreased polarity of the solutions. Furthermore, the cloud points increase with increasing side chain length indicating lower solubility corresponding to the hydrophobicity of the polymers.

The cloud points of the UCST transitions of the poly(2-oxazoline)s with aromatic substituents, $\mathrm{PhOx}$ and BenzOx, are depicted in Figure 4, right. The higher hydrophobicity of the BenzOx is clearly evidenced in the higher cloud points as well as a shift of the transitions to higher ethanol content. Furthermore, it is observed that these polymer show similar behavior as the poly(2-alkyl-2-oxazoline)s in the second group comprising side-chains with intermediate hydrophobicity. As such, it can be concluded that a favorable hydration shell is also formed with these aromatic poly(2-oxazoline)s as was previously already reported for $\mathrm{PhOx}$ [33].

Detailed investigations on the dissolution upon heating behavior of the polymers were also performed and the dissolution temperatures in the first heating run are plotted as function of the ethanol content in Figure 5. The higher dissolution temperature of the i-ButOx can be directly related to the higher melting transition $\left(\mathrm{Tm}=200{ }^{\circ} \mathrm{C}\right.$ ) [52] of a solid sample compared to the poly(2-n-alkyl-2-oxazoline)s that all have a melting transition close to $150{ }^{\circ} \mathrm{C}$ [45]. Even though the melting transition temperatures of the poly(2-n-alkyl-2-oxazoline)s are all similar, the increasing dissolution temperatures with increasing side-chain length can be related to the increased crystalline fraction of the copolymers as evidenced by the larger area of the melting transition, i.e., larger melting enthalpy [45]. 
Figure 4. Cloud points as function of wt $\%$ ethanol for the UCST transitions of the poly(2-alkyl-2-oxazoline)s (left) as well as poly(2-phenyl-2-oxazoline) ( $\mathrm{PhOx}$ ) and poly(2-benzyl-2-oxazoline) (BenzOx; right) determined at $5 \mathrm{mg} / \mathrm{mL}$.
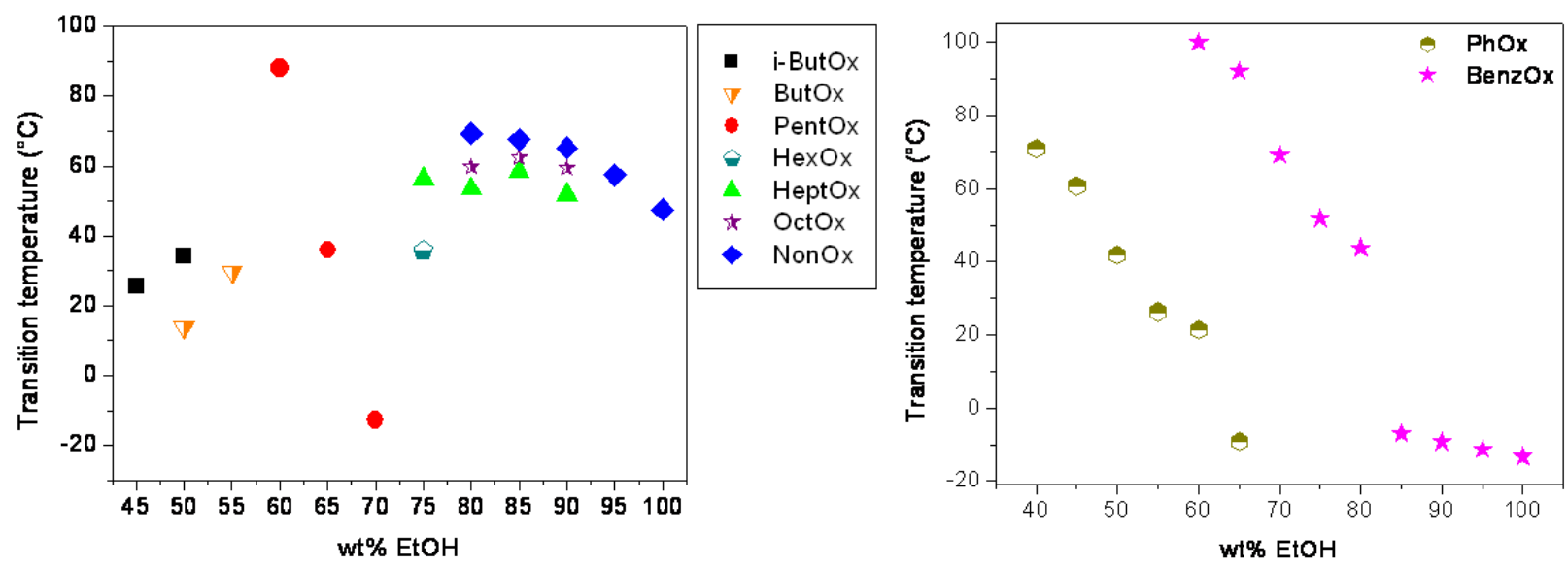

Figure 5. Dissolution temperatures in the first heating run for the poly(2-alkyl-2-oxazoline)s as function of wt\% ethanol $(5 \mathrm{mg} / \mathrm{mL})$.

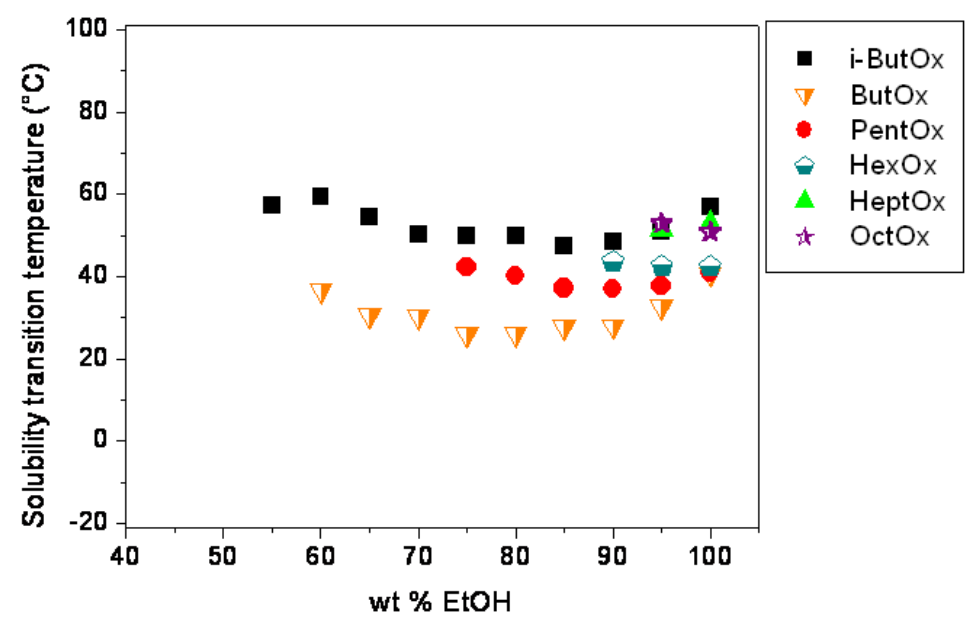

\section{Experimental Section}

The monomer synthesis and subsequent polymerization of the poly(2-oxazoline)s with varying alkyl side chain are described elsewhere [45,46]. All investigated polymers (DP 60) have a relatively narrow molar mass distribution with a polydispersity index around 1.20 as obtained by SEC investigations.

Before analysis the polymers were dried overnight at $40{ }^{\circ} \mathrm{C}$ under reduced pressure. The samples were prepared by weighing the polymer $(5.0 \pm 0.2 \mathrm{mg})$ in a sample vial followed by addition of $1.0 \mathrm{~mL}$ of the desired mixture of ethanol (Biosolve) and deionized water (Laborpure, Behr Labor Technik). The solubility screening was performed on these samples in the temperature range from $-20{ }^{\circ} \mathrm{C}\left(0{ }^{\circ} \mathrm{C}\right.$ for water) to $105{ }^{\circ} \mathrm{C}$ with heating and cooling ramps of $1{ }^{\circ} \mathrm{C} \min ^{-1}$ under stirring. During these controlled heating and cooling cycles (two cycles per sample), the transmission through the solutions was monitored in a Crystal 16 TM from Avantium Technologies [53]. In the Crystal 16 four blocks of four parallel temperature controlled sample holders are connected to a Julabo FP40 cryostat 
allowing 16 simultaneous measurements. All vials were visually inspected after the heating program to facilitate the interpretation of the observed transmission profiles. Polymer-solvent combinations that gave unexpected transmission profiles were remeasured and the solution was visually inspected at different stages during the heating run. The presented cloud point and dissolution temperatures correspond to the dissolution temperature or precipitation temperature at $50 \%$ transmittance from the second heating run.

\section{Conclusions}

The solubility transitions of various poly(2-oxazoline)s in ethanol-water solvent mixtures were investigated by turbidimetry. As expected, MeOx and EtOx (DP 60) were soluble in all solvent compositions at all investigated temperatures. Polymers with isopropyl and $n$-propyl side chains revealed LCST transitions in water and water rich ethanol solutions. Further increasing the hydrophobicity of the side chain rendered the polymers insoluble up to the presence of $35 \mathrm{wt} \%$ of ethanol. These polymers revealed UCST phase transition in between the insoluble and soluble (after heating) ethanol-water concentration regimes. The ethanol content required for the UCST transitions increased with increasing hydrophobicity of the polymer side chains. Detailed investigations on the cloud point of the UCST transition revealed three groups of polymers having a small hydrophobic side chain, an intermediate aliphatic or aromatic side chain, or a large hydrophobic side chain that shields the hydrophilic amide groups in the polymer backbone. The evolution of the UCST cloud points could be related to the hydrophilic-hydrophobic balance of the groups of polymers on one hand and the ethanol-water solvent structure on the other hand.

These detailed insights in the solution behavior of poly(2-oxazoline)s in ethanol-water solvent mixtures will be important for the design and development of poly(2-oxazoline)s for applications in personal care and medicine where both ethanol and water are commonly used solvents.

\section{Acknowledgements}

The Netherlands Scientific Organisation (NWO; Veni-grant RH and Vici-award USS) and the Dutch Polymer Institute (DPI; project numbers 449 and 612) are acknowledged for financial support.

\section{References and Notes}

1. Tomalia, D.A.; Sheetz, D.P. Homopolymerization of 2-alkyl- and 2-aryl-2-oxazolines. J. Polym. Sci. A Polym. Chem. 1966, 4, 2253-2265.

2. Seeliger, W.; Aufderhaar, E.; Diepers, W.; Feinauer, R.; Nehring, R.; Thier, W.; Hellmann, H. Recent syntheses and reactions of cyclic imidic esters. Angew. Chem. 1966, 20, 913-927.

3. Kagiya, T.; Narisawa, S.; Maeda, T.; Fukui, K. Ring-opening polymerization of 2-substituted 2oxazolines. Polym. Lett. 1966, 4, 441-445.

4. Bassiri, T.G.; Levy, A.; Litt, M. Polymerization of cyclic imino ethers. I. Oxazolines. Polym. Lett. 1967, 5, 871-879.

5. Hoogenboom, R. Poly(2-oxazoline)s: A polymer class with numerous potential applications. Angew. Chem. Int. Ed. 2009, 48, 7978-7994. 
6. Adams, N.; Schubert, U.S. Poly(2-oxazolines) in biological and biomedical application contexts. Adv. Drug Delivery Rev. 2007, 59, 1504-1520.

7. Knop, K.; Hoogenboom, R.; Fischer, D.; Schubert, U.S. Poly(ethylene glycol) in drug delivery: Pros and cons as well as potential alternatives. Angew. Chem. Int. Ed. 2010, doi: 10.1002/anie.200902672.

8. Schlaad, H.; Diehl, C.; Gress, A.; Meyer, M.; Demirel, A.L.; Nur, Y.; Bertin, A. Poly(2-oxazoline)s as smart bioinspired polymers. Macromol. Rapid Commun. 2010, 31, 511-525.

9. Kim, K.T.; Cornelissen, J.J.L.M.; Nolte, R.J.M.; van Hest, J.C.M. Polymeric monosaccharide receptors responsive at neutral pH. J. Am. Chem. Soc. 2009, 131, 13908-13909.

10. Qing, G.; Wang, X.; Fuchs, H.; Sun, T. Nucleotide-responsive wettability on a smart polymer surface. J. Am. Chem. Soc. 2009, 131, 8370-8371.

11. Amir, R.J., Zhong, S., Pochan, D.J.; Hawker, C.J. Enzymatically triggered self-assembly of block copolymers. J. Am. Chem. Soc. 2009, 131, 13949-13951.

12. Davis, D.A.; Hamilton, A.; Yang, J.; Cremar, L.D.; van Gough, D.; Potisek, S.L.; Ong, M.T.; Braun, P.V.; Martínez, T.J.; White, S.R.; MooreJ. S.; Sottos, N.R. Force-induced activation of covalent bonds in mechanoresponsive polymeric materials. Nature 2009, 459, 68-72.

13. Piermattei, A.; Karthikeyan, S.; Sijbesma, R.P. Activating catalysts with mechanical force. Nat. Chem. 2009, 1, 133-137.

14. Sershen, S.R.; Westcott, S.L.; Halas, N.J.; West, J.L. Temperature-sensitive polymer-nanoshell composites for photothermally modulated drug delivery. J. Biomed. Mater. Res. 2000, 51, 293-298.

15. Keurentjes, J.T.F.; Kemmere, M.F.; Bruinewoud, H.; Vertommen, M.A.M.E.; Rovers, S.A.; Hoogenboom, R.; Stemkens, L.F.S.; Peters, F.L.A.M.A.; Tielen, N.J.C.; van Asseldonk, D.T.A.; Gabriel, A.F.; Joosten, E.A.; Marcus, M.A.E. Externally triggered glass transition switch for localized on-demand drug delivery. Angew. Chem. Int. Ed. 2009, 48, 9867-9870.

16. Wood, K.C.; Zacharia, N.S.; Schmidt, D.J.; Wrightman, S.N.; Andaya, B.J.; Hammond, P.T. Electroactive controlled release thin films. Proc. Natl. Acad. Sci. USA 2008, 105, 2280-2285.

17. Hergt, R.; Hiergeist, R.; Hilger, I.; Kaiser, W.A.; Lapatnikov, Y.; Margel, S.; Richter, U. Maghemite nanoparticles with very high AC-losses for application in RF-magnetic hyperthermia. J. Magnetism Magn. Mater. 2004, 270, 345-357.

18. Schild, H.G. Poly(N-isopropylacrylamide): Experiment, theory and application. Prog. Polym. Sci. 1992, 17, 163-249.

19. Russell, T.P. Surface responsive materials. Science 2002, 297, 964-967.

20. Oosten, C.L.; Bastiaansen, C.W.M.; Broer, D.J. Printed artificial cilia from liquid-crystal network actuators modularly driven by light. Nat. Mater. 2009, 8, 677-682.

21. Koopmans, C.; Ritter, H. Color change of $N$-isopropylacrylamide copolymer bearing Reichardts dye as optical sensor for lower critical solution temperature and for host-guest interaction with $\beta$-cyclodextrin. J. Am. Chem. Soc. 2007, 129, 3502-3503.

22. Gota, C.; Okabe, K.; Funatsu, T.; Harada, Y.; Uchiyama, S. Hydrophilic fluorescent nanogel thermometer for intracellular thermometry. J. Am. Chem. Soc. 2009, 131, 2766-2767.

23. Pietsch, C.; Hoogenboom, R.; Schubert, U.S. Soluble polymeric dual sensor for temperature and pH value. Angew. Chem. Int. Ed. 2009, 48, 5653-5656. 
24. Kudaibergenov, S.; Jaeger, W.; Laschewsky, A. Polymeric betaines: Synthesis, characterization and application. Adv. Polym. Sci. 2006, 201, 157-224.

25. Dimitrov, I.; Trzebicka, B.; Mueller, A.H.E.; Dworak, A.; Tsvetanov, C.B. Thermosensitive water-soluble copolymers with doubly responsive reversibly interacting entities. Prog. Polym. Sci. 2007, 32, 1275-1343.

26. Costa, R.O.R.; Freitas, R.F.S. Phase behavior of poly(N-isopropylacrylamide) in binary aqueous solutions. Polymer 2002, 43, 5879-5885.

27. Lin, P.; Clash, C.; Pearce, E.M.; Kwei, T.K.; Aponte, M.A. Solubility and miscibility of poly(ethyl oxazoline). J. Polym. Sci. B Polym. Phys. 1988, 26, 603-619.

28. Uyama, H.; Kobayashi, S. A novel thermo-sensitive polymer. Poly(2-iso-propyl-2-oxazoline). Chem. Lett. 1992, 21, 1643-1646.

29. Park, J.-S.; Kataoka, K. Comprehensive and accurate control of thermosensitivity of poly(2-alkyl-2-oxazoline)s via well-defined gradient or random copolymerization. Macromolecules 2007, 40, 3599-3609.

30. Hoogenboom, R.; Thijs, H.M.L.; Jochems, M.J.H.C.; van Lankvelt, B.M.; Fijten, M.W.M.; Schubert, U.S. Tuning the LCST of poly(2-oxazoline)s by varying composition and molecular weight: alternatives to poly( $N$-isopropylacrylamide)? Chem. Commun. 2008, 44, 5758-5760.

31. Afroze, F.; Nies, E.; Berghmans, H. Phase transitions in the system poly(N-isopropylacrylamide)/water and swelling behaviour of the corresponding networks. $J$. Mol. Struct. 2000, 554, 55-68.

32. Christova, D.; Velichkova, R.; Loos, W.; Goethals, E.J.; Du Prez, F. New thermo-responsive polymer materials based on poly(2-ethyl-2-oxazoline) segments. Polymer 2003, 44, 2255-2261.

33. Meyer, M.; Antonietti, M.; Schlaad, H. Unexpected thermal characteristics of aqueous solutions of poly(2-isopropyl-2-oxazoline). Soft Matter 2007, 3, 430-431.

34. Demirel, A.L.; Meyer, M.; Schlaad, H. Formation of polyamide nanofibers by directional crystallization in aqueous solution. Angew. Chem. Int. Ed. 2007, 46, 8622-8624.

35. Hoogenboom, R.; Thijs, H.M.L.; Wouters, D.; Hoeppener, S.; Schubert, U.S. Tuning solution polymer properties by binary water-ethanol solvent mixtures. Soft Matter 2008, 4, 103-107.

36. Lambermont-Thijs, H.M.L.; Hoogenboom, R.; Fustin, C.-A.; Bomal-D’Haese, C.; Gohy, J.-F.; Schubert, U.S. Solubility behavior of amphiphilic block and random copolymers based on 2-ethyl-2-oxazoline and 2-nonyl-2-oxazoline in binary water-ethanol mixtures. J. Polym. Sci. A Polym. Chem. 2009, 47, 515-522.

37. Hoogenboom, R.; Lambermont-Thijs, H.M.L.; Jochems, M.J.H.C.; Hoeppener, S.; Guerlain, C.; Fustin, C.-A.; Gohy, J.-F.; Schubert, U.S. A schizophrenic gradient copolymer: switching and reversing poly(2-oxazoline) micelles based on UCST and subtle solvent changes. Soft Matter 2009, 5, 3590-3592.

38. Shultz, A.R.; Flory, P.J. Phase equilibria in polymer-solvent systems. III. Three-component systems. J. Am. Chem. Soc. 1953, 75, 5681-5685.

39. Wolf, B.A.; Blaum, G. Measured and calculated solubility of polymers in mixed solvents: Monotony and cosolvency. J. Polym. Sci. B Polym. Phys. 1975, 13, 1115-1132. 
40. Frank, H.S.; Evans, M.W. Free volume and entropy in condensed systems iii. Entropy in binary liquid mixtures; partial molal entropy in dilute solutions; structure and thermodynamics in aqueous electrolytes. J. Chem. Phys. 1945, 13, 507-532.

41. Franks, F.; Ives, D.J.G. The structural properties of alcohol-water mixtures. Q. Rev. Chem. Soc. 1966, 20, 1-44.

42. Noskov, S.Y.; Lamoureux, G.; Roux, B. Molecular dynamics study of hydration in ethanol-water mixtures using a polarizable force field. J. Phys. Chem. B 2005, 109, 6705-6713.

43. Escalera, J.B.; Bustamante, P.; Martin, A. Predicting the solubility of drugs in solvent mixtures: Multiple solubility maxima and the chameleonic effect. J. Pharm. Pharmacol. 1994, 46, 172-175.

44. Bustamante, P.; Navarro, J.; Romero, S.; Escalera, B. Thermodynamic origin of the solubility profile of drugs showing one or two maxima against the polarity of aqueous and nonaqueous mixtures: niflumic acid and caffeine. J. Pharm. Sci. 2002, 91, 874-883.

45. Piccarolo, S.; Titomanlio, G. Synergism in the swelling and solubility of poly(methyl methacrylate) in presence of ethanol/water mixtures. Makromol. Chem. Rapid Commun. 1982, 3, 383-387.

46. Hoogenboom, R.; Rogers, S.; Can, A.; Becer, C.R.; Guerrero-Sanchez, C.; Wouters, D.; Hoeppener, S.; Schubert, U.S. Self-assembly of double hydrophobic block copolymers in water-ethanol mixtures: From micelles to thermo-responsive micellar gels. Chem. Commun. 2009, 37, 5582-5584.

47. Hoogenboom, R.; Fijten, M.W.M.; Thijs, H.M.L.; van Lankvelt, B.M.; Schubert, U.S. Microwave-assisted synthesis and properties of a series of poly(2 alkyl-2-oxazoline)s. Des. Monomers Polym. 2005, 8, 659-671.

48. Kempe, K.; Lobert, M.; Hoogenboom, R.; Schubert, U.S. Screening the synthesis of 2-substituted-2-oxazolines. J. Comb. Chem. 2009, 11, 274-280.

49. Beom Lee, S.; Cong, S.-C.; Jin, J.-I.; Sohn, Y.S. Solvent effect on the lower critical solution temperature of biodegradable thermosensitive poly(organophosphazenes). Polym. Bull. 2000, 45, 389-396.

50. Bharatiya, B.; Guo, C.; Ma, J.H.; Hassan, P.A.; Bahadur, P. Aggregation and clouding behavior of aqueous solution of EO-PO block copolymer in presence of n-alkanols. Eur. Polym. J. 2007, 43, 1883-1891.

51. Hoogenboom, R.; Becer, C.R.; Guerrero-Sanchez, C.; Hoeppener, S.; Schubert, U.S. Solubility and thermoresponsiveness of PMMA in alcohol-water solvent mixtures. Aust. J. Chem. 2010, 63, doi: 10.1071/CH10083.

52. Kempe, K.; Lobert, M.; Hoogenboom, R.; Schubert, U.S. Synthesis and characterization of a series of diverse poly(2-oxazoline)s. J. Polym. Sci. A Polym. Chem. 2009, 47, 3829-3838.

53. Birch, M.; Fussel, S.J.; Higginson, P.D.; McDowall, N.; Marziano, I. Towards a PAT-based strategy for crystallization development. Org. Process. Res. Dev. 2005, 9, 360-364.

(C) 2010 by the authors; licensee MDPI, Basel, Switzerland. This article is an Open Access article distributed under the terms and conditions of the Creative Commons Attribution license (http://creativecommons.org/licenses/by/3.0/). 